\title{
Pax6 Is Required for Making Specific Subpopulations of Granule and Periglomerular Neurons in the Olfactory Bulb
}

\author{
Minoree Kohwi, ${ }^{1}$ Noriko Osumi, ${ }^{3}$ John L. R. Rubenstein, ${ }^{2}$ and Arturo Alvarez-Buylla ${ }^{1}$ \\ ${ }^{1}$ Department of Neurological Surgery and Program in Developmental and Stem Cell Biology and ${ }^{2}$ Center for Neurobiology and Psychiatry, University of \\ California, San Francisco, San Francisco, California 94143, and ${ }^{3}$ Division of Developmental Neuroscience, Center for Translational and Advanced Animal \\ Research, Tohoku University School of Medicine, Sendai 980-8575, Japan
}

The subventricular zone (SVZ) produces different subclasses of olfactory bulb (OB) interneurons throughout life. Little is known about the molecular mechanisms controlling the production of different types of interneurons. Here we show that most proliferating adult SVZ progenitors express the transcription factor Pax6, but only a small subpopulation of migrating neuroblasts and new OB interneurons derived from these progenitors retains Pax6 expression. To elucidate the cell-autonomous role of Pax6 in OB neurogenesis, we transplanted green fluorescent protein-expressing embryonic forebrain progenitors of the dorsal lateral ganglionic eminence from Pax6 mutant Small Eye (Pax6 ${ }^{\text {Sey/Sey }}$ ) mice into the SVZ of adult wild-type mice. Pax6 ${ }^{\text {Sey/Sey }}$ progenitors produce neuroblasts capable of migrating into the $\mathrm{OB}$ but fail to generate dopaminergic periglomerular and superficial granule cells. Interestingly, superficial granule neurons also express mRNA for tyrosine hydroxylase, the rate-limiting enzyme in dopamine synthesis. Our data show that SVZ neuroblasts are heterogeneous and that Pax6 is required in a cell-autonomous manner for the production of cells in the dopaminergic lineage.

Key words: adult neurogenesis; olfactory bulb; dopaminergic periglomerular cells; interneurons; Sey; mouse

\section{Introduction}

Neurogenesis continues in two germinal layers of the adult brain, the subgranular zone (SGZ) of the dentate gyrus (Palmer et al., 1999) and the SVZ of the lateral walls of the lateral ventricles (Alvarez-Buylla and Garcia-Verdugo, 2002). Cells born in the SVZ migrate a long distance to the olfactory bulb $(\mathrm{OB})$ and mature into two main types of interneurons, periglomerular cells (PGCs) and granule cells (GCs) (Alvarez-Buylla and GarciaVerdugo, 2002).

New OB interneurons appear to replace older neurons that die (Winner et al., 2002). The function of this continual replacement is not understood but may be related to olfactory discrimination (Gheusi et al., 2000; Cecchi et al., 2001). Both PGCs and GCs modulate the activity of major output neurons in the $\mathrm{OB}$ and therefore are considered essential for olfactory processing (Shepherd and Greer, 1998). Although considerable progress has been made in understanding the cellular organization of the SVZ and the mechanisms by which neuroblasts migrate and differentiate in the OB (Lois and Alvarez-Buylla, 1994; Petreanu and AlvarezBuylla, 2002; Schaar et al., 2004), little is known regarding molecular mechanisms that underlie adult SVZ neurogenesis. In

Received April 12, 2005; revised June 7, 2005; accepted June 9, 2005.

This work was supported by grants from the National Institutes of Health. We are grateful to the members of the Alvarez-Buylla laboratory for critical reading of this manuscript. We thank Dr. Thomas Jessell for providing us with the rabbit anti-ER81 antibody. We thank Dr. Verónica Martínez Cerdeño for her help with imaging.

Correspondence should be addressed to Dr. Arturo Alvarez-Buylla, Department of Neurological Surgery and Program in Developmental and Stem Cell Biology, University of California San Francisco School of Medicine, 513 Parnassus Avenue, Health Sciences West 1201, San Francisco, CA 94143-0525. E-mail: abuylla@itsa.ucsf.edu.

DOI:10.1523/JNEUROSCI.1435-05.2005

Copyright $\odot 2005$ Society for Neuroscience $\quad$ 0270-6474/05/256997-07\$15.00/0 particular, it is not known how SVZ neuroblasts acquire specific neuronal phenotypes.

The transcription factor Pax6 is essential during the development of many tissues, including eyes, brain, and endocrine glands (Simpson and Price, 2002). Homozygous Small Eye (Pax6 Sey/Sey) embryos lack functional Pax6 protein and die at birth (Hill et al., 1991). During embryonic development, Pax6 is expressed in the olfactory placodes, epithelium, and bulbs (Stoykova and Gruss, 1994), among other tissues, and these structures fail to form (Hill et al., 1991) in Pax6 ${ }^{\text {Sey/Sey }}$ animals. In the adult brain, Pax6 is expressed in the $\mathrm{OB}$ in the granule cell layer (GCL) and glomerular layer (Stoykova and Gruss, 1994; Dellovade et al., 1998), suggesting that it may be involved in adult SVZ neurogenesis. Interestingly, a previous study has shown that the number of dopaminergic PGCs in Pax6 heterozygotes is significantly reduced (Dellovade et al., 1998). This suggested that Pax6 could play an important role in the generation of different subtypes of OB interneurons formed in the adult brain; however, because Pax6 also plays a critical role in $\mathrm{OB}$ and olfactory epithelial development (Hill et al., 1991), it was not possible to determine whether the effects of Pax6 loss were cell autonomous or secondary to other defects in the development of the olfactory system.

Given the potential clinical importance of dopaminergic cell production from adult progenitors (Baker et al., 2001), we investigated Pax6 expression patterns during adult SVZ neurogenesis. We found that Pax6 was expressed in most proliferating SVZ progenitors but only in a subpopulation of migrating neuroblasts, indicating that migrating neuroblasts are molecularly heterogeneous. To determine the role of Pax6 in this lineage, we studied the fate of Pax6 ${ }^{\text {Sey/Sey }}$ precursors grafted into the wildtype SVZ environment. This approach allowed us to analyze the 
cell-autonomous effects of Pax6 loss without the confounding effects that this mutation has on the olfactory epithelium and $O B$. Our results show that Pax6 is essential for the generation of dopaminergic PGCs and a specific subpopulation of GCs. In contrast, other neurons appeared to be born, to migrate, and to differentiate normally in the absence of Pax6. These data show that Pax6 is required cell autonomously for the production of specific subclasses of $\mathrm{OB}$ interneurons.

\section{Materials and Methods}

Bromodeoxyuridine injections. Adult CD-1 animals were injected intraperitoneally once with the DNA synthesis marker bromodeoxyuridine (BrdU) at $50 \mathrm{mg} / \mathrm{kg}$ and killed at different survival times for analyses.

Genotyping. Genotypes of grafted embryos were confirmed as described previously (Hill et al., 1991).

Transplantation. Animal care and procedures were approved by the University of California San Francisco Institutional Animal Care Committees. Pax6 ${ }^{\text {Sey/Sey }}$ and green fluorescent protein (GFP) mice were maintained on a CD-1 background. Dorsal lateral ganglionic eminence (dLGE) from embryonic day 16.5 (E16.5) timed-pregnant Pax6 ${ }^{\mathrm{Sey} / \mathrm{Sey}}$ embryos and wild-type littermates were harvested and then transplanted into the SVZ of adult CD-1 mice at the following stereotaxic coordinates: anteroposterior (AP), $0.5 \mathrm{~mm}$; mediolateral (ML), $1.1 \mathrm{~mm}$; dorsoventral (DV), $1.7 \mathrm{~mm}$; AP, $1 \mathrm{~mm}$; ML, $1 \mathrm{~mm}$; DV, $2.3 \mathrm{~mm}$. Results from wildtype littermates were the same as from CD-1 wild-type embryos expressing GFP; therefore, results were pooled. Brains from grafted animals were removed after intracardial perfusion with $4 \%$ paraformaldehyde and cut into $50 \mu \mathrm{m}$ sections on a vibratome.

Cultured SVZ explants. SVZ explants from postnatal day 3 CD-1 pups were dissected and cultured in Matrigel in Neurobasal media (Invitrogen, Gaithersburg, MD) supplemented with B27 (Invitrogen) as described previously (Wichterle et al., 1997). Cultures were fixed in $4 \%$ paraformaldehyde $48 \mathrm{~h}$ later and immunostained as described below.

Immunohistochemistry. The following primary antibodies were used: sheep anti-GFP, 1:500 (Biogenesis, Sandown, NH); rabbit anti-Pax6, 1:200 (Covance, Princeton, NJ); rabbit anti-Pax6, 1:100 (Osumi et al., 1997); mouse anti-Mash1, 1:200 (PharMingen, San Diego, CA); rabbit anti-ER81, 1:4000 (kind gift from T. Jessell, Columbia University, New York, NY); rabbit-anti-tyrosine hydroxylase (TH), 1:500 (Pel-Freeze, Rogers, AZ); rat anti-BrdU, 1:10 (Oxford Biotech, Oxford, UK); mouse anti- $\beta$ III tubulin, 1:500 (Covance); mouse anti-neuronal-specific nuclear protein (NeuN), 1:200 (Chemicon, Temecula, CA); and mouse anti-glutamic acid decarboxylase 67, 1:1000 (Sigma, St. Louis, MO). The following secondary antibodies were used: donkey anti-sheep 488, donkey anti-rabbit 594, donkey anti-rat 488 , donkey anti-mouse 594, and donkey anti-mouse 488 (all Alexa Fluors were used at 1:500; Molecular Probes, Eugene, OR). Sections were blocked with $10 \%$ serum and $0.1 \%$ Triton X-100. Primary antibodies were incubated at $4^{\circ} \mathrm{C}$ overnight, and secondary antibodies were incubated for $1 \mathrm{~h}$ at room temperature. For Pax6-BrdU double-labeling, the Pax6 signal was amplified with tyramide (kit 15; Molecular Probes) according to the manufacturer's protocol. Sections were counterstained with $4^{\prime}, 6^{\prime}$-diamidino-2-phenylindole and analyzed with an Olympus (Tokyo, Japan) AX70 light microscope. For quantifying GFP-TH double-labeling, each $\mathrm{GFP}^{+}$cell was imaged at $40 \times$, and colabeling was confirmed by matching cellular morphologies. For BrdU labeling, vibratome sections were treated with $2 \mathrm{~N} \mathrm{HCl}$ for 30 $\mathrm{min}$ at $37^{\circ} \mathrm{C}$ and $0.1 \mathrm{~m}$ boric acid for $10 \mathrm{~min}$ at room temperature before antibody incubation. NeuN was visualized with either Alexa 594 secondary antibody or diaminobenzidine.

In situ hybridization. Fresh-frozen cryostat sections $(10 \mu \mathrm{m})$ from adult CD-1 animals were stained for the TH mRNA probe. In situ hybridization was performed with a modified protocol that has been described previously (Yun et al., 2001). Briefly, probes were labeled with digoxigenin (DIG) (Roche Products, Welwyn Garden City, UK), detected with an anti-DIG antibody coupled to alkaline phosphatase (Roche Products), and visualized with nitroblue tetrazolium chloride-5bromo-4-chloro-3-indolyl-phosphate (Roche Products). For fluorescent in situ antibody double-labeling, an anti-DIG-horseradish peroxi- dase antibody was used with tyramide-Alexa Fluor 488 (Molecular Probes) for RNA detection before staining for NeuN antibody as described above. Images were taken with an Olympus AX70 light microscope.

\section{Results \\ Pax6 is expressed by rapidly proliferating cells in the adult SVZ and by a subset of migrating neuroblasts}

To characterize Pax6 ${ }^{+}$cells in the adult SVZ, we used one injection of BrdU (an analog of thymidine) to label dividing cells, and we determined, at different survival times, the proportion of $\mathrm{BrdU}^{+}$cells that expressed Pax6. One hour after BrdU injection, most $(85 \%) \mathrm{BrdU}^{+}$cells in the SVZ were Pax6 ${ }^{+}$(Fig. 1a,b). At this time point, more than one-half of the dividing cells in the SVZ corresponded to highly proliferative transit-amplifying progenitors, the type C cells (Doetsch et al., 1997). Recent studies indicate that these cells express the basic helix-loop-helix transcription factor Mash1 (Parras et al., 2004). By immunostaining for Mash1 and Pax6, we found that most (82\%) SVZ Mash1 ${ }^{+}$ cells coexpressed Pax6 (Fig. 1d). Interestingly, $18 \%$ of Mash ${ }^{+}$ cells were Pax6 ${ }^{-}$; conversely, $24 \%$ of Pax $6^{+}$cells were Mash1-. This could be caused by different combinations of transcription factors being expressed in different populations of SVZ progenitors or by the differences in the temporal regulation of these transcription factors in SVZ cells. The above observation indicates that many, if not all, dividing SVZ progenitors (likely type $\mathrm{C}$ cells) express Pax6.

At longer survival times, and as new neurons are formed and migrate to the $\mathrm{OB}$, we observed a sharp decrease in the proportion of BrdU-Pax6 double-labeled cells (Fig. 1a). By 5 d after BrdU administration, $\mathrm{BrdU}^{+}$cells were mostly migratory neuroblasts in the rostral migratory stream (RMS) and core of the OB; of these BrdU-labeled cells, only $32 \%$ were Pax $6^{+}$. Pax6 expression by migrating neuroblasts has been observed previously (Hack et al., 2004). Consistently, our data indicate that a subpopulation of these cells expresses Pax6. This proportion continued to decrease ( $21 \%$ at $15 \mathrm{~d}$ after BrdU), and by $45 \mathrm{~d}$ after BrdU injection, only $13 \%$ of the new cells expressed Pax6 (Fig. 1a,c). By $45 \mathrm{~d}, \mathrm{BrdU}^{+}$cells have matured into functional neurons and are stably integrated into the $\mathrm{OB}$ circuit (Petreanu and AlvarezBuylla, 2002; Carleton et al., 2003).

Our data suggest that after an early wave of Pax6 expression by most proliferating SVZ progenitors, most newly formed cells downregulate this transcription factor, resulting in only a subset of migrating neuroblasts that are $\mathrm{Pax}^{+}$. Immunostaining for Pax6 and markers for migrating neuroblasts confirmed that a subpopulation of neuroblasts in the SVZ and RMS expresses Pax6 (Fig. 2a). We confirmed this observation with SVZ explant cultures in which neuroblasts migrate out in chains essentially devoid of other cell types (Wichterle et al., 1997) (Fig. 2b). These results show that although neuroblasts of the SVZ and RMS appear to have a similar morphology and express similar molecular markers (Cremer et al., 1994; Anderson et al., 1999; Brown et al., 2003; Schaar et al., 2004), they are heterogeneous in terms of Pax6 expression.

Previous studies have shown that dopaminergic PGCs are generated in the adult brain (Winner et al., 2002). By $45 \mathrm{~d}$ after BrdU injection, $8 \%$ of newly formed GCs and 29\% of newly formed PGCs expressed Pax6 (supplemental Fig. 1, available at www.jneurosci.org as supplemental material). Interestingly, we found that a similar proportion (26\%) of BrdU-labeled PGCs at $40 \mathrm{~d}$ express $\mathrm{TH}$, the rate-limiting enzyme in dopamine synthesis (supplemental Fig. 2, available at www.jneurosci.org as supplemental material). This suggested that new Pax $6^{+}$cells in the 

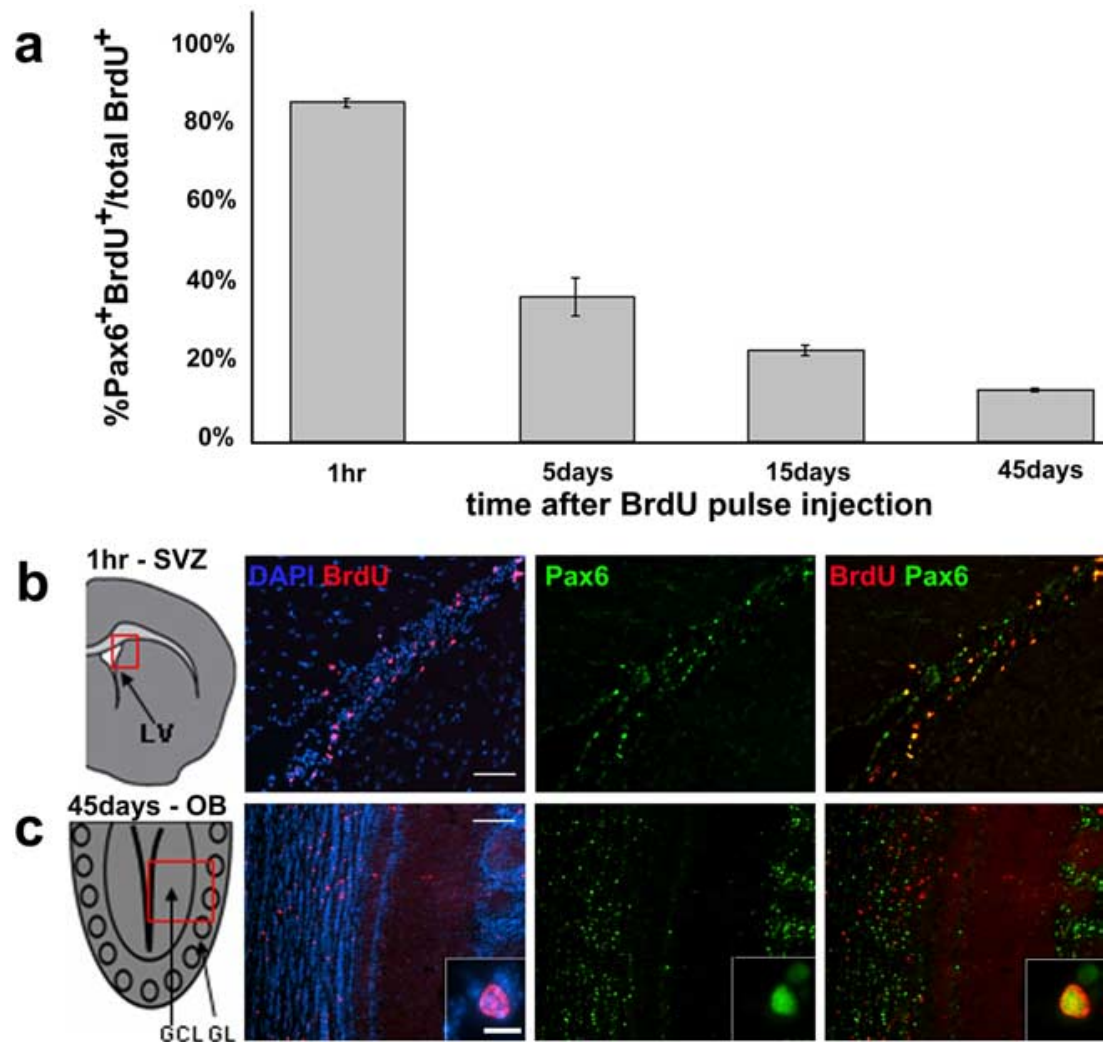

d
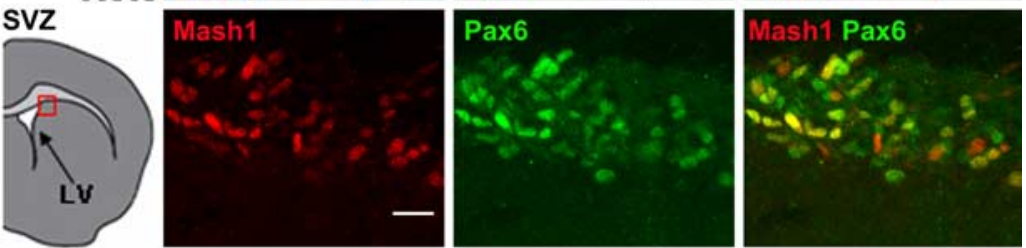

Figure 1. Dynamics of Pax6 expression during adult SVZ neurogenesis. $\boldsymbol{a}$, Quantification of BrdU-Pax6 double-labeled cells among total BrdU ${ }^{+}$cells counted at $1 \mathrm{~h}$ ( $n=431$ cells from 3 mice), $5 \mathrm{~d}$ ( $n=1274$ cells from 3 mice), $15 \mathrm{~d}$ ( $n=1701$ cells from 3 mice), and $45 \mathrm{~d}$ ( $n=2125$ cells from 3 mice) after a single BrdU injection. $\boldsymbol{b}, \boldsymbol{c}$, Representative pictures of BrdU-Pax6 labeling at $1 \mathrm{~h}$ and $45 \mathrm{~d}$ after BrdU injection. The box in the schematic on the left indicates the region from which the pictures were taken. Arrows indicate examples of double-labeled cells. $\boldsymbol{c}$, Inset, High magnification of one BrdU-Pax6 double-labeled cell in the OB. $\boldsymbol{d}$, Mash1 (red) and Pax6 (green) double-staining in the SVZ. GL, Glomerular layer. Scale bars: $\boldsymbol{b}, 50 \mu \mathrm{m} ; \boldsymbol{c}, 100 \mu \mathrm{m} ; \boldsymbol{c}$, inset, $10 \mu \mathrm{m} ; \boldsymbol{d}, 20 \mu \mathrm{m}$. Error bars indicate SEM. in vivo

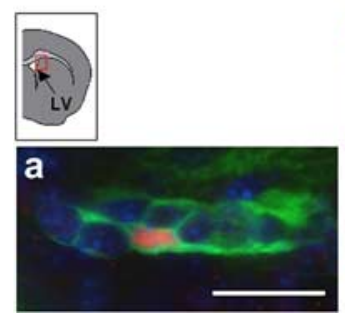

in vitro
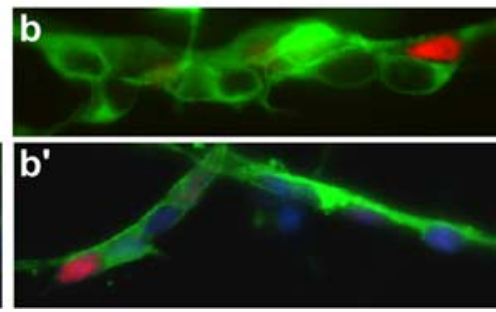

Figure 2. Migrating neuroblasts from the SVZ are molecularly heterogeneous. $\boldsymbol{a}$, Here we show in the SVZ a chain of several migrating neuroblasts with elongated nuclei. Pax 6 is expressed by a subset of these cells. The schematic shows the region of the SVZ in $\boldsymbol{a} . \boldsymbol{b}, \boldsymbol{b}^{\prime}$, Two examples of chains of migrating neuroblasts from an SVZ explant showing heterogeneity among migrating neuroblasts with respect to Pax6 expression. The early neuronal marker $\beta$ III tubulin appears green, and Pax6 appears red. LV, Lateral ventricle. Scale bar (in $\boldsymbol{a}$ ): $\boldsymbol{a}-\boldsymbol{b}^{\prime}, 20 \mu \mathrm{m}$.

glomerular layer may differentiate into dopaminergic cells. This hypothesis is reinforced by the observation that most $\mathrm{TH}^{+}$PGCs express Pax6 (Stoykova and Gruss, 1994; Dellovade et al., 1998). Our data show that Pax6 labels a subpopulation of migratory neuroblasts in the RMS and a subpopulation of newly formed OB neurons; therefore, we hypothesized that Pax6 may be necessary for the generation of specific $\mathrm{OB}$ interneuron subtypes.

Dopaminergic periglomerular cells are lost in the Pax6 ${ }^{\text {Sey/Sey }}$ grafts

Because homozygous Pax6 $6^{\text {Sey/Sey }}$ mice fail to form OBs and die at birth (Hill et al., 1991), we grafted dLGE (a region of the ganglionic eminence in which Pax6 is expressed) of individual Pax6 ${ }^{\text {Sey/Sey }}$ E16.5 embryos into the SVZ of adult wild-type mice. Pax $6^{\text {Sey/Sey }}$ mice were crossed to mice expressing GFP under the control of the $\beta$-actin promoter, so that all of the grafted cells could be followed by GFP expression. Grafting Pax $6^{\text {Sey/Sey }}$ cells into the adult wild-type SVZ allowed us to follow the fate of Pax $6^{\text {Sey/Sey }}$ cells in the wild-type RMS and the intact laminar structure within the OB. This approach also allowed us to analyze the cell-autonomous effects of Pax6 without the confounding effects of the lack of Pax6 on the development of the olfactory epithelium.

Pax6 ${ }^{\text {Sey/Sey }}$ progenitors were capable of generating cells that migrate to the $\mathrm{OB}$ and develop into both GCs and PGCs (Figs. 3-5). In fact, the proportion of cells found in the core of the $\mathrm{OB}$ (still tangentially migrating neuroblasts), glomerular layer, and GCL at $40 \mathrm{~d}$ after transplantation was similar between wild-type and Pax6 $6^{\text {Sey/Sey }}$ grafted animals (Fig. 3), indicating that Pax6 ${ }^{\text {Sey/Sey }}$ cells can populate the glomerular layer and GCL in proportions similar to those of the wildtype cells. These cells had neuronal morphologies with extensive branching and dendritic spines (supplemental Fig. 3, available at www.jneurosci.org as supplemental material) as observed in fully differentiated, new OB interneurons (Petreanu and Alvarez-Buylla, 2002). Grafted Pax6 ${ }^{\text {Sey/Sey }}$ cells also expressed NeuN, a marker of differentiated neurons (Monje et al., 2003) (Figs. 4d, 5). Furthermore, these cells expressed Gad67, indicating that they differentiated into GABAergic interneurons (Figs. $4 e, 5)$. Thus, Pax6 is not essential for the production of these cells, their tangential migration into the $\mathrm{OB}$, or their differentiation into neurons. However, we found that Pax6 was essential for the formation of specific subtypes of OB interneurons. A dramatic decrease in the proportion of dopaminergic PGCs was observed in Pax6 $6^{\text {Sey/Sey }}$ grafts compared with wild-type controls (Fig. 4a). At $40 \mathrm{~d}$ after the graft, $27.7 \%$ of all PGCs derived from the wild-type graft were $\mathrm{TH}^{+}$ (Fig. 4a). In contrast, only one $\mathrm{TH}^{+} \mathrm{PGC}(1.0 \%)$ was observed in the $\mathrm{OB}$ when mutant Pax6 $6^{\text {Sey/Sey }}$ cells were grafted (Fig. $4 a$ ). Importantly, we observed a reduction in $\mathrm{TH}^{+}$PGCs even from Pax6 heterozygous mice ( $\mathrm{Pax} 6^{\mathrm{Sey} /+}$; one cell or $1.5 \%$ ), indicating that dopaminergic PGCs cell autonomously require both alleles of Pax6.

\section{Superficial granule cells are lost in the Pax $6^{\text {Sey/Sey }}$ graft}

Although it is known that some GCs express Pax6 (Stoykova and Gruss, 1994), previous studies did not observe that this transcrip- 
tion factor is required for the development of a specific subpopulation of GCs (Dellovade et al., 1998). Strikingly, we found that Pax6 ${ }^{\text {Sey/Sey }}$ graft-derived neurons in the GCL were not evenly distributed but were restricted to the deep regions of the layer (Fig. 5c). It has been suggested that deep GCs mostly contact the mitral cells, whereas superficial GCs preferentially contact tufted cells, suggesting important functional differences between these two neuronal populations (Shepherd and Greer, 1998). Recent studies have shown that the transcription factor ER81 is expressed predominantly in the superficial layer of the GCL (Stenman et al., 2003) (supplemental Fig. 4, available at www. jneurosci.org as supplemental material). By using ER81 expression as a superficial GCL marker, we found that control wild-type grafts generated evenly distributed GCs in both the superficial and deep GCL at $40 \mathrm{~d}$ (51.4\% in ER81-high, superficial layer) (Fig. $5 a, d$ ). In contrast, we found that Pax6 ${ }^{\text {Sey/Sey }}$ graft-derived cells predominantly localized to the deep, ER81-low region of the GCL (only $5.0 \%$ in the superficial layer) (Fig. $5 c, d$ ). We noticed an intermediate effect on the distribution of PGCs $(34.6 \%$ in the superficial GCL) (Fig. 5b,d) in heterozygous Pax6 ${ }^{\text {Sey/+ }}$ grafts.

To further characterize the Pax $6^{\text {Sey/Sey }}$ graft-derived neurons, we analyzed their dendritic arborization within the external plexiform layer (EPL) (Fig. $5 a^{\prime}-c^{\prime}$ ) (supplemental Fig. 4, available at www.jneurosci.org as supplemental material). Deep and superficial GCs have unique dendritic patterns within the EPL. Deep GCs have somas within the deep GCL and extend their dendrites to the deep EPL, whereas superficial GCs have somas within the superficial layers of the GCL and extend their dendrites to the superficial EPL (Orona et al., 1983). We found that wild-type graft-derived neurons send dendritic arbors uniformly within the EPL (Fig. $4 a^{\prime}$ ), whereas those from the Pax $6^{\text {Sey/Sey }}$ grafts send their processes to only the deep EPL (Fig. $4 c^{\prime}$ ), consistent with the location of their somas in the deep GCL. Thus, although $\mathrm{Pax}^{\mathrm{Sey} / \mathrm{Sey}}$ progenitors can form GCs, they fail to generate a specific subpopulation that localizes to the superficial GCL. The lack of superficial GCs from Pax6 ${ }^{\text {Sey/Sey }}$ grafts does not appear to be caused by impaired radial migration, because we found that many PGCs that migrated to the most superficial layers of the $\mathrm{OB}$, the glomerular layer, and both the glomerular layer and GCL are similarly populated between the Pax6 ${ }^{\text {Sey/Sey }}$ and wild-type grafts (Figs. 3-5). It is possible, however, that Pax $6^{\text {Sey/Sey }}$-derived cells have a migratory defect that affects only superficial GCs.

$\mathrm{TH}$ protein expression is observed mostly in the glomerular layer in a subpopulation of PGCs (Fig. 6a); however, a previous study showed that some cells in the GCL express TH mRNA and suggested that they may correspond to young $\mathrm{TH}^{+}$ PGCs in transit to the glomerular layer (Baker et al., 2001). By using in situ hybridization, we confirmed that a subpopulation of cells in the GCL expressed $\mathrm{TH}$ mRNA (Fig. 6b). Interestingly, these cells are predominately in the superficial GCL (Fig. $6 a^{\prime}, b$ ). We next performed double in situ hybridization immunohistochemistry for $T H$ mRNA and NeuN protein, a marker for mature neurons (Monje et al., 2003), and found that the $\mathrm{TH} \mathrm{mRNA}^{+}$cells in the superficial GCL coexpress NeuN, indicating that these cells are mature resident neurons of the superficial GCL (Fig. $6 b, c$ ).

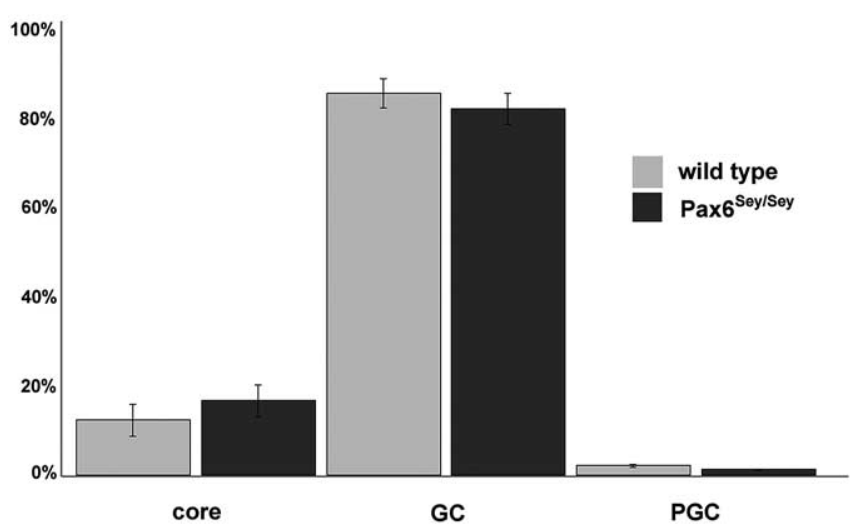

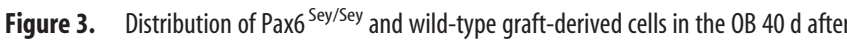
grafting. Note the similar distributions of $\mathrm{GFP}^{+}$cells found in all layers of the $0 \mathrm{~B}$ between wild-type and $\mathrm{Pax} 6^{\text {Sey/Sey }}$ grafts, indicating that $\mathrm{Pax}^{\mathrm{Sey} / \mathrm{Sey}}$-derived cells can migrate both tangentially and radially in the $\mathrm{OB}$. For the Pax6 $6^{\text {Sey/Sey }}$ graft, $n=1491$ cells (3 mice). For the wild-type graft, $n=2511$ cells ( 3 mice). Error bars indicate SEM.
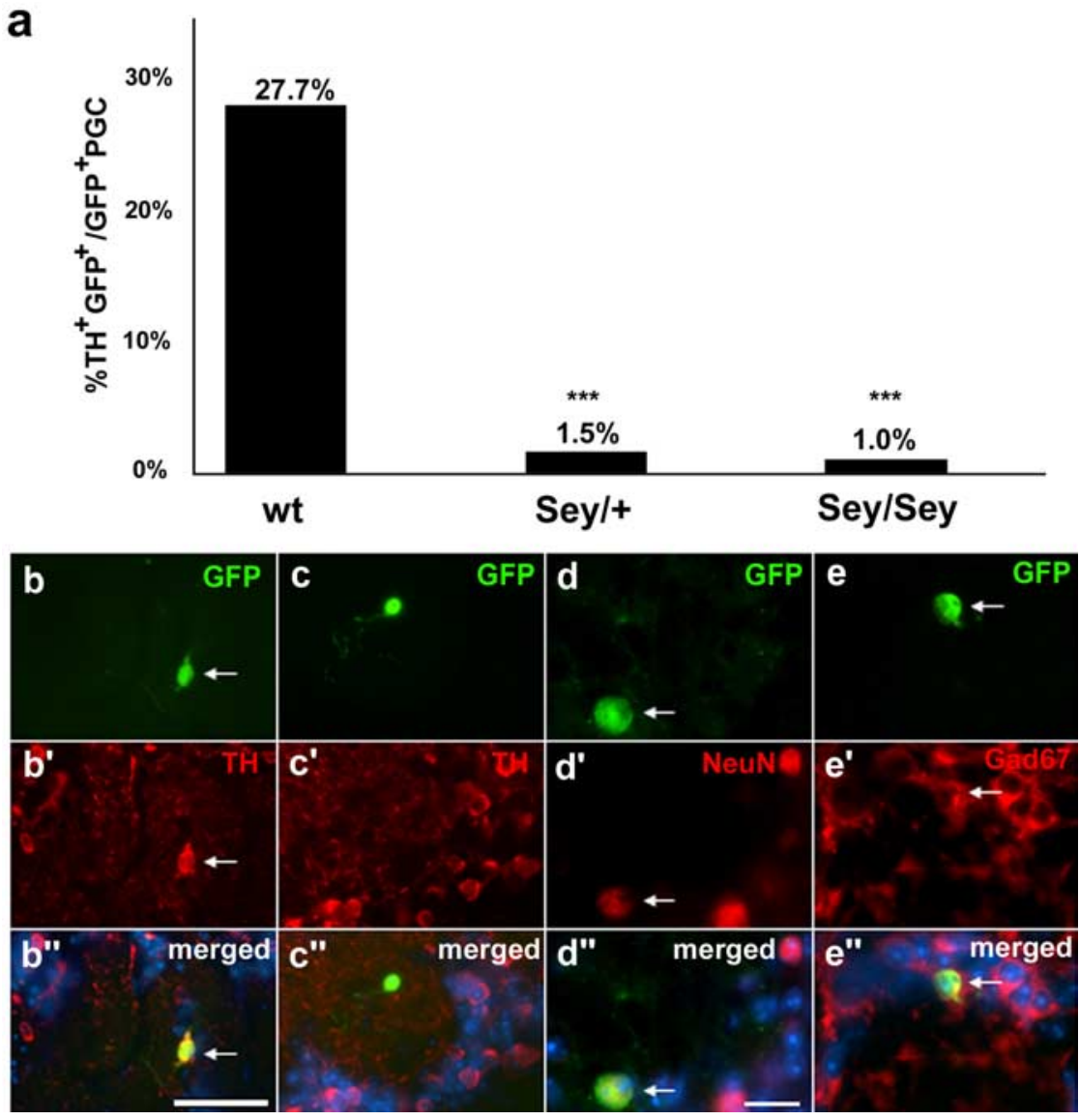

Figure 4. Loss of dopaminergic PGCs from Pax6 ${ }^{\text {Sey/Sey }}$ graft. $\boldsymbol{a}$, Quantification of the percentage of $\mathrm{TH}^{+}$cells from a graft among total graft-derived PGCs at 40 d of survival; wild type, $n=202$ cells ( 5 mice); Pax $6^{\text {Sey } /+}, n=68$ cells ( 4 mice); Pax ${ }^{\text {Sey/Sey }}$, $n=96$ cells ( 6 mice). $\boldsymbol{b}$, Example of a GFP-TH double-labeled cell. Note identical morphology, confirming colabeling of the same cell. $\boldsymbol{c}$, Example of a TH-negative GFP cell. $\boldsymbol{d}$, Representative picture of a graft-derived cell from a Pax6 $6^{\text {Sey/Sey }}$ graft coexpressing a mature neuronal marker, NeuN. $\boldsymbol{e}$, The GABAergic neuronal marker, Gad67. Scale bars: (in $\boldsymbol{b}^{\prime \prime}$ ) $\boldsymbol{b}-\boldsymbol{c}^{\prime \prime}, 50 \mu \mathrm{m}$; (in $\boldsymbol{d}^{\prime \prime}$ ) $\boldsymbol{d}-\boldsymbol{e}^{\prime \prime}, 20 \mu \mathrm{m}$. Statistical analysis with $\chi^{2}$ test; $p<0.001$. 

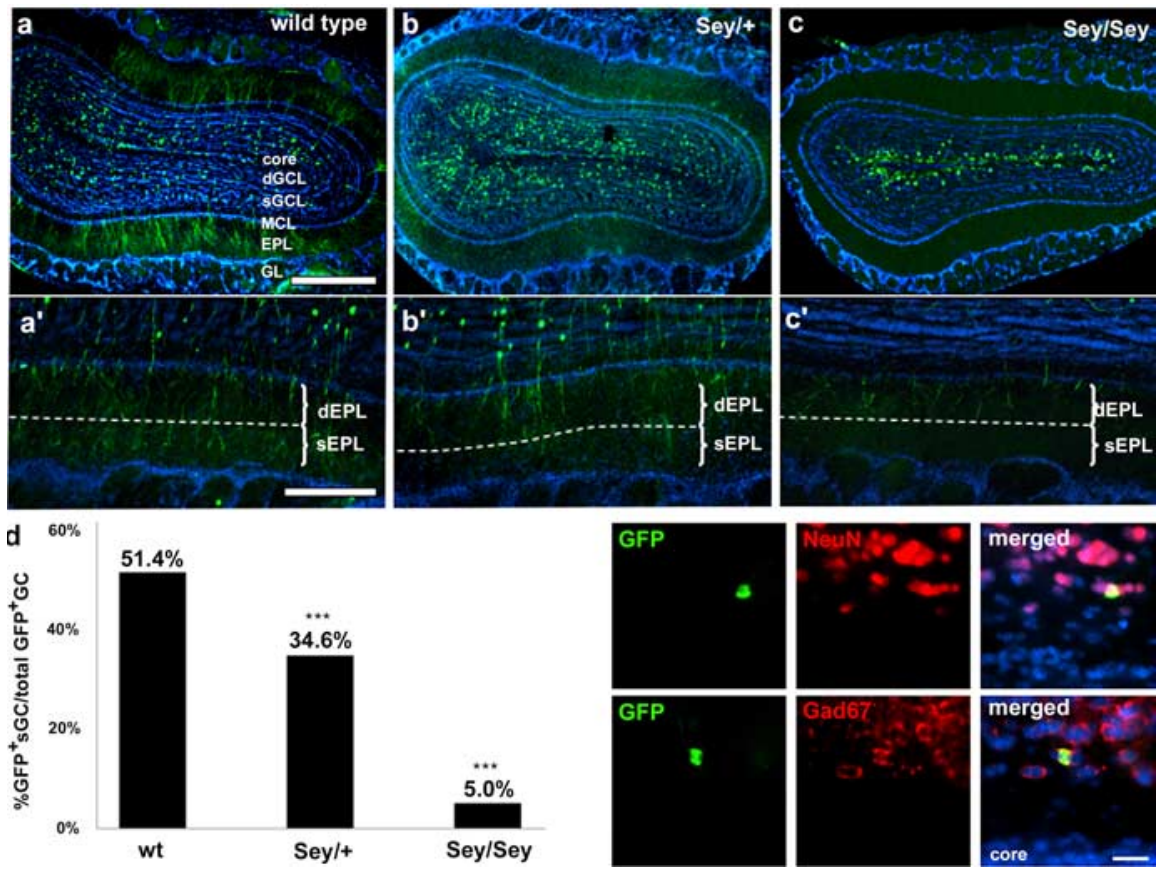

Figure 5. Superficial GCs are lost from the Pax6 $6^{\text {Sey/Sey }}$ graft. $\boldsymbol{a}, \mathrm{GFP}{ }^{+}$cells from a wild-type graft are distributed uniformly throughout the $\mathrm{GCL}\left(2 \times\right.$ magnification). $\boldsymbol{b}, \mathrm{GFP}^{+}$cells from a Pax $6^{\text {Sey/+ }}$ graft show an intermediate phenotype between wild type and Pax6 ${ }^{\text {Sey/Sey }}$ ( $2 \times$ magnification). $c$, GFP $^{+}$cells from a Pax $6^{\text {Sey/Sey }}$ graft are predominantly localized to the deep GCL $(2 \times$ magnification). Scale bar (in $\boldsymbol{a}) \boldsymbol{a}-\boldsymbol{c}^{\prime}, 1 \mathrm{~mm}$. $\boldsymbol{d}$, Quantification of percentage of superficial GCs among total GFP ${ }^{+} \mathrm{GCs}$ at $40 \mathrm{~d}$ of survival: wild type, $n=4268$ (5 mice); Pax6 ${ }^{\text {Sey/+ }}, n=1246$ ( 4 mice); Pax6 ${ }^{\text {Sey/Sey }}, n=2168$ (5 mice). Statistical analysis with $\chi^{2}$ test; $p<0.001$. Dendrites from wild-type graft-derived cells arborize uniformly throughout the EPL $\left(\boldsymbol{a}^{\prime}\right)$ but extend to only the deep EPL from Pax6 ${ }^{\text {Sey/Sey }}$ graft-derived cells $\left(\boldsymbol{c}^{\prime}\right)$. Scale bar (in $\left.\boldsymbol{a}^{\prime}\right) \boldsymbol{a}^{\prime}-\boldsymbol{c}^{\prime}, 200 \mu \mathrm{m}$. Representative images of GFP ${ }^{+}$cells double-labeled with a marker for mature neurons, NeuN, and a marker for GABAergic neurons, Gad67, are shown. Note that GFP ${ }^{+}$ cells are in the deep $\mathrm{GCL}$ and not in the core of the $\mathrm{OB}$ where neuroblasts are still migrating tangentially. $\mathrm{dGCL}$, Deep $\mathrm{GCL}$; $s \mathrm{GCL}$, superficial GCL; GL, glomerular layer; dEPL, deep EPL; sEPL, superficial EPL; sGC, superficial GC; wt, wild type.

\section{Discussion}

The main findings of this study are as follows: (1) Pax6 is expressed by most proliferating progenitor cells; (2) Pax6 is downregulated rapidly but is present in a small subpopulation of migrating neuroblasts and newly formed OB neurons; and (3) Pax6 is not required for the generation, migration, or differentiation of $\mathrm{OB}$ neurons but is essential in a cell-autonomous manner for the generation of specific subtypes of GCs and PGCs.

Pax6 expression in proliferating adult SVZ progenitors is reminiscent of its expression in embryonic progenitors of the telencephalon. In the developing brain, Pax6 is expressed predominantly in the dorsal telencephalon and in a descending gradient in the ventral telencephalon. In contrast, Mash1 displays the opposite expression pattern, being expressed predominantly by the ventral telencephalon, and overlaps with Pax6 in the dLGE (Toresson et al., 2000; Yun et al., 2001). Our observations that Pax6 and Mash1 expression extensively overlap in the adult SVZ is consistent with the hypothesis that this adult germinal zone is derived from the dLGE (Stenman et al., 2003). The expression of Pax6 in actively proliferating cells, together with the overlap with Mash1, suggests that transient amplifying $C$ cells express this transcription factor, but other proliferating cells like B and A cells may also contain Pax6. In fact, we found that a small subpopulation of SVZ GFAP ${ }^{+}$cells expresses this transcription factor (M. Kohwi and A. Alvarez-Buylla, unpublished observations), suggesting that Pax6 is expressed in progenitors cells quite early in the lineage.

In contrast to proliferating progenitors, Pax6 is expressed by a Pax6 ${ }^{\text {Sey/Sey }}$ progenitor cells into adult wild-type SVZ allowed us to directly investigate the cell-autonomous effects of Pax6 protein loss.

It is known that the production of GCs and PGCs of the OB begins in the LGE of the embryo (Wichterle et al., 2001). These processes continue into adulthood, and analyses of adult SVZ by markers, function, and location have suggested that this region is equivalent to all, or part, of the embryonic LGE (Porteus et al., 1994; Corbin et al., 2000; Stenman et al., 2003). In fact, the behavior of LGE progenitors grafted into the adult brain is indistinguishable from that of adult SVZ progenitors grafted homotopically (Wichterle et al., 1999). We infer that the cells we are grafting are similar, if not equivalent, to those found in the adult. Consistent with this notion, the proportion of $\mathrm{TH}^{+} \mathrm{PGCs}$ among total PGCs produced during adult neurogenesis (supplemental Fig. 2, available at www.jneurosci.org as supplemental material) is similar to that derived from grafting embryonic wild-type dLGE progenitors into the adult SVZ (Fig. 4a). These observations suggest that despite the age difference between graft and host in our transplantation paradigm, the behavior of the grafted progenitors mirrors their adult counterparts in generating specific subtypes of $\mathrm{OB}$ interneurons; however, we cannot rule out the possibility that the dependence of the embryonic LGE progenitor on Pax6 may be affected by placement in an adult neurogenic environment. It will be interesting to analyze the role of Pax6 in adult progenitors with a conditional loss-of-function allele. Our data show conclusively that progenitors from the Pax6 $6^{\text {Sey/Sey }}$ forebrain cell autonomously require both alleles of 


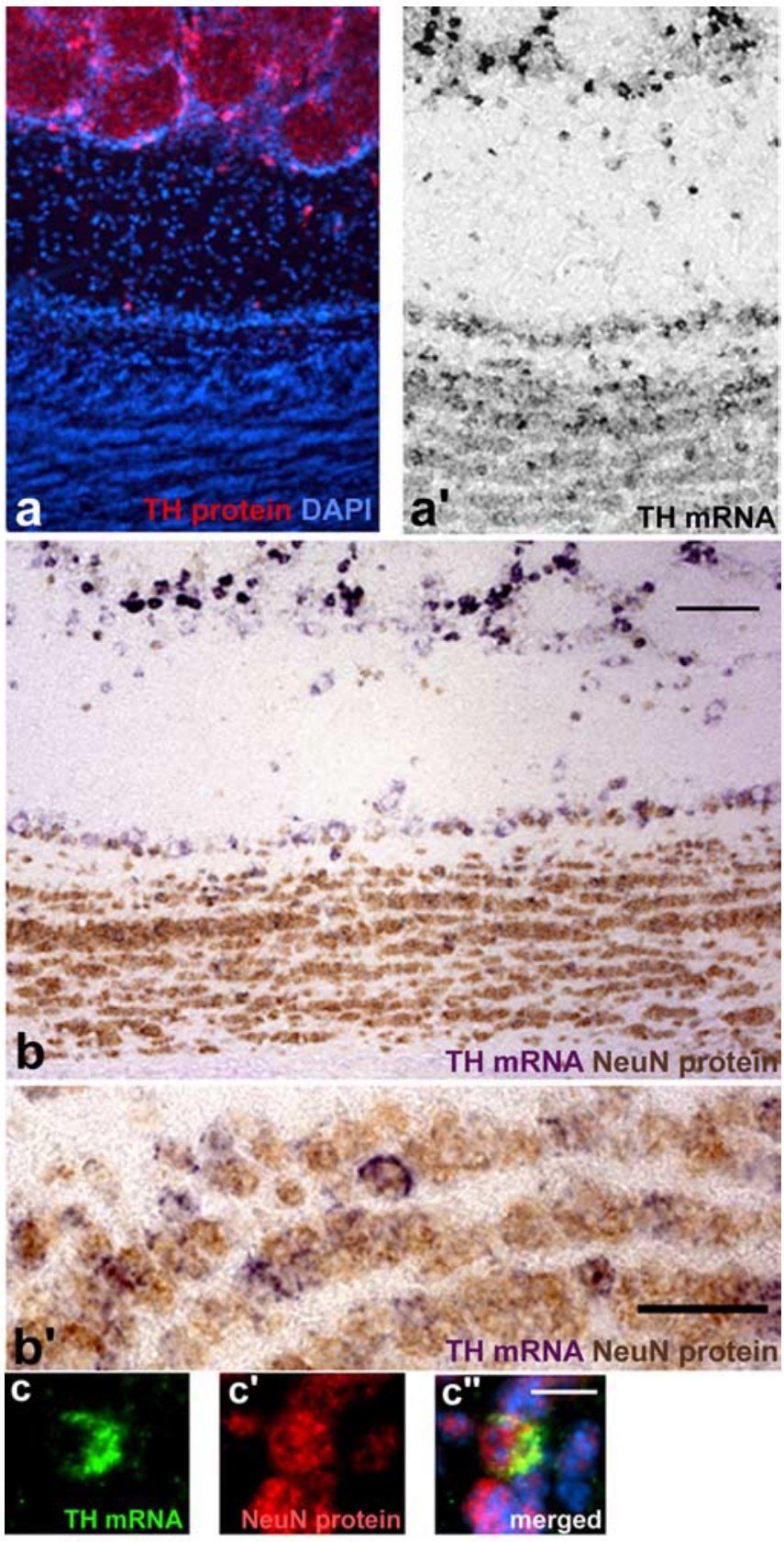

Figure 6. TH expression in the adult OB. $\boldsymbol{a}$, TH protein expression localized predominantly in the $0 \mathrm{~B}$ glomerular layer. $\boldsymbol{a}^{\prime}, T H$ mRNA is present in the superficial $\mathrm{GCL}$ in addition to the glomerular layer. $\boldsymbol{b}, \boldsymbol{b}^{\prime}, T H \mathrm{mRNA}$-expressing cells coexpress the mature neuronal marker NeuN. $\boldsymbol{c}^{\prime}$, Double-labeled $T H$ mRNA and NeuN protein by fluorescence in situ hybridization and immunohistochemistry. Scale bars: $\boldsymbol{b}, 100 \mu \mathrm{m} ; \boldsymbol{b}^{\prime}, 30 \mu \mathrm{m} ; \boldsymbol{c}^{\prime \prime}, 20 \mu \mathrm{m}$.

Pax6 for the production of dopaminergic PGCs, thus explaining the previous observation that dopaminergic PGCs are reduced in Pax6 heterozygous animals (Dellovade et al., 1998). Pax6 may be required for the birth, migration, and/or differentiation of this particular cell type.

Pax6 heterozygotes also have a reduced GCL (Dellovade et al., 1998), suggesting that Pax6 may also be involved in the generation of GCs or that nonautonomous effects in heterozygotes affected the development of the GCL. Quite unexpectedly, we found in our transplantation experiment with $\mathrm{Pax}^{\mathrm{Sey} / \mathrm{Sey}}$ progenitors that most superficial GCs do not form. The physiological properties of superficial versus deep GCs formed in the adult brain also differ (Carleton et al., 2003), supporting the notion that superficial and deep GCs contribute to the OB function in unique ways (Orona et al., 1983) and depend on different molecular programs for their generation.

Interestingly, previous reports of homochronically transplanting Pax6 ${ }^{\text {Sey/Sey }}$ progenitors from the embryonic cortical ventricular zone into wild-type cortex showed that neurons arising from the $\mathrm{Pax}^{\mathrm{Sey} / \mathrm{Sey}}$ progenitors were able to migrate and differentiate normally within the wild-type environment (Caric et al., 1997). These data suggested that migration defects of lateborn cortical Pax6 ${ }^{\text {Sey/Sey }}$ cells are caused by a non-cellautonomous defect of the environment in which cortical cells migrate; however, in the retina, Pax6 mutation causes a cellautonomous defect (Marquardt et al., 2001). Our results differ from those in the developing cortex and suggest that in the SVZ-OB system, as in the retina, Pax6 functions in a cellautonomous manner to specify certain cell types.

TH mRNA-expressing cells have been detected in the GCL by in situ hybridization but not by immunocytochemistry. It was reasoned that these cells correspond to progenitors of immature dopaminergic PGCs migrating through the GCL on their way to the glomerular layer (Baker et al., 2001); however, the number of TH mRNA-expressing cells in the superficial GCL is much larger than the small number of newly formed PGCs that are normally formed. Moreover, most of the TH mRNA-expressing cells in the superficial GCL do not have the elongated morphology of radially migrating young neurons but have nuclei of shape and size similar to those of neighboring GCs (Fig. $6 b^{\prime}$ ). We found that superficial GCs that expressed TH mRNA also expressed the mature neuronal marker NeuN, indicating that these cells had completed their neuronal maturation within the GCL into GCs. It is not possible to simultaneously detect $T H$ RNA and GFP protein to determine whether superficially localized GCs from our grafts express $T H$ mRNA; however, the precise localization of $T H$ mRNA-expressing GCs to the superficial layers of the GCL and the dramatic decrease of superficial GCs in our graft of Pax6 $6^{\text {Sey/Sey }}$ progenitors suggest that Pax6 may be involved in the generation of dopaminergic $\mathrm{OB}$ interneurons in both the glomerular layer and the GCL.

Our work shows that the transcription factor Pax6 is required for the production of a specific subpopulation of $\mathrm{OB}$ neurons. This work also suggests that the types of neuroblasts produced in the adult SVZ are heterogeneous, much like in the embryo (Temple, 2001): young neurons may be predetermined by the expression of specific sets of transcription factors in the SVZ or during their migration in the RMS. Understanding the molecular mechanism by which different types of neurons and, in particular, dopaminergic cells are produced in the adult germinal centers may have important therapeutic implications for the treatment of neurological disorders such as Parkinson's disease.

\section{References}

Alvarez-Buylla A, Garcia-Verdugo JM (2002) Neurogenesis in adult subventricular zone. J Neurosci 22:629-634.

Anderson S, Mione M, Yun K, Rubenstein JL (1999) Differential origins of neocortical projection and local circuit neurons: role of dlx genes in neocortical interneuronogenesis. Cereb Cortex 9:646-654.

Baker H (1990) Unilateral, neonatal olfactory deprivation alters tyrosine hydroxylase expression but not aromatic amino acid decarboxylase or GABA immunoreactivity. Neuroscience 36:761-771.

Baker H, Liu N, Chun HS, Saino S, Berlin R, Volpe B, Son JH (2001) Phenotypic differentiation during migration of dopaminergic progenitor cells to the olfactory bulb. J Neurosci 21:8505-8513.

Brown JP, Couillard-Despres S, Cooper-Kuhn CM, Winkler J, Aigner L, 
Kuhn HG (2003) Transient expression of doublecortin during adult neurogenesis. J Comp Neurol 467:1-10.

Caric D, Gooday D, Hill RE, McConnell SK, Price DJ (1997) Determination of the migratory capacity of embryonic cortical cells lacking the transcription factor Pax-6. Development 124:5087-5096.

Carleton A, Petreanu LT, Lansford R, Alvarez-Buylla A, Lledo PM (2003) Becoming a new neuron in the adult olfactory bulb. Nat Neurosci 6:507-518.

Cecchi GA, Petreanu LT, Alvarez-Buylla A, Magnasco MO (2001) Unsupervised learning and adaptation in a model of adult neurogenesis. J Comput Neurosci 11:175-182.

Corbin JG, Gaiano N, Machold RP, Langston A, Fishell G (2000) The Gsh2 homeodomain gene controls multiple aspects of telencephalic development. Development 127:5007-5020.

Cremer H, Lange R, Christoph A, Plomann M, Vopper G, Roes J, Brown R, Baldwin S, Kraemer P, Scheff S, Barthels D, Rajewsky K, Wille W (1994) Inactivation of the $\mathrm{N}-\mathrm{CAM}$ gene in mice results in size reduction of the olfactory bulb and deficits in spatial learning. Nature 367:455-459.

Dellovade TL, Pfaff DW, Schwanzel-Fukuda M (1998) Olfactory bulb development is altered in small-eye (Sey) mice. J Comp Neurol 402:402-418

Doetsch F, Garcia-Verdugo JM, Alvarez-Buylla A (1997) Cellular composition and three-dimensional organization of the subventricular germinal zone in the adult mammalian brain. J Neurosci 17:5046-5061.

Gheusi G, Cremer H, McLean H, Chazal G, Vincent JD, Lledo PM (2000) Importance of newly generated neurons in the adult olfactory bulb for odor discrimination. Proc Natl Acad Sci USA 97:1823-1828.

Hack MA, Sugimori M, Lundberg C, Nakafuku M, Gotz M (2004) Regionalization and fate specification in neurospheres: the role of Olig2 and Pax6. Mol Cell Neurosci 25:664-678.

Hill RE, Favor J, Hogan BL, Ton CC, Saunders GF, Hanson IM, Prosser J, Jordan T, Hastie ND, van Heyningen V (1991) Mouse small eye results from mutations in a paired-like homeobox-containing gene. Nature 354:522-525.

Jimenez D, Garcia C, de Castro F, Chedotal A, Sotelo C, de Carlos JA, Valverde F, Lopez-Mascaraque L (2000) Evidence for intrinsic development of olfactory structures in Pax-6 mutant mice. J Comp Neurol 428:511-526.

Lois C, Alvarez-Buylla A (1994) Long-distance neuronal migration in the adult mammalian brain. Science 264:1145-1148.

Marquardt T, Ashery-Padan R, Andrejewski N, Scardigli R, Guillemot F, Gruss P (2001) Pax6 is required for the multipotent state of retinal progenitor cells. Cell 105:43-55.

Monje ML, Toda H, Palmer TD (2003) Inflammatory blockade restores adult hippocampal neurogenesis. Science 302:1760-1765.

Nomura T, Osumi N (2004) Misrouting of mitral cell progenitors in the Pax6/small eye rat telencephalon. Development 131:787-796.

Orona E, Scott JW, Rainer EC (1983) Different granule cell populations innervate superficial and deep regions of the external plexiform layer in rat olfactory bulb. J Comp Neurol 217:227-237.
Osumi N, Hirota A, Ohuchi H, Nakafuku M, Iimura T, Kuratani S, Fujiwara M, Noji S, Eto K (1997) Pax-6 is involved in the specification of hindbrain motor neuron subtype. Development 124:2961-2972.

Palmer TD, Markakis EA, Willhoite AR, Safar F, Gage FH (1999) Fibroblast growth factor- 2 activates a latent neurogenic program in neural stem cells from diverse regions of the adult CNS. J Neurosci 19:8487-8497.

Parras CM, Galli R, Britz O, Soares S, Galichet C, Battiste J, Johnson JE, Nakafuku M, Vescovi A, Guillemot F (2004) Mash1 specifies neurons and oligodendrocytes in the postnatal brain. EMBO J 23:4495-4505.

Petreanu L, Alvarez-Buylla A (2002) Maturation and death of adult-born olfactory bulb granule neurons: role of olfaction. J Neurosci 22:6106-6113.

Porteus MH, Bulfone A, Liu J-K, Puelles L, Lo L-C, Rubenstein JLR (1994) DLX-2, MASH-1, and MAP-2 expression and bromodeoxyuridine incorporation define molecularly distinct cell populations in the embryonic mouse forebrain. J Neurosci 14:6370-6383.

Schaar BT, Kinoshita K, McConnell SK (2004) Doublecortin microtubule affinity is regulated by a balance of kinase and phosphatase activity at the leading edge of migrating neurons. Neuron 41:203-213.

Shepherd GM, Greer CA (1998) Olfactory bulb. In: The synaptic organization of the brain, Ed 4 (Shepherd GM, ed), pp 159-203. New York: Oxford UP.

Simpson TI, Price DJ (2002) Pax6: a pleiotropic player in development. BioEssays 24:1041-1051.

Stenman J, Toresson H, Campbell K (2003) Identification of two distinct progenitor populations in the lateral ganglionic eminence: implications for striatal and olfactory bulb neurogenesis. J Neurosci 23:167-174.

Stoykova A, Gruss P (1994) Roles of Pax-genes in developing and adult brain as suggested by expression patterns. J Neurosci 14:1395-1412.

Temple S (2001) The development of neural stem cells. Nature 414:112-117.

Toresson H, Potter SS, Campbell K (2000) Genetic control of dorsal-ventral identity in the telencephalon: opposing roles for Pax6 and Gsh2. Development 127:4361-4371.

Wichterle H, Garcia-Verdugo JM, Alvarez-Buylla A (1997) Direct evidence for homotypic, glia-independent neuronal migration. Neuron 18:779-791.

Wichterle H, Garcia-Verdugo JM, Herrera DG, Alvarez-Buylla A (1999) Young neurons from medial ganglionic eminence disperse in adult and embryonic brain. Nat Neurosci 2:461-466.

Wichterle H, Turnbull DH, Nery S, Fishell G, Alvarez-Buylla A (2001) In utero fate mapping reveals distinct migratory pathways and fates of neurons born in the mammalian basal forebrain. Development 128:3759-3771.

Winner B, Cooper-Kuhn CM, Aigner R, Winkler J, Kuhn HG (2002) Longterm survival and cell death of newly generated neurons in the adult rat olfactory bulb. Eur J Neurosci 16:1681-1689.

Yun K, Potter S, Rubenstein JL (2001) Gsh2 and Pax6 play complementary roles in dorsoventral patterning of the mammalian telencephalon. Development 128:193-205. 